\title{
EDUCAÇÃO DO CAMPO E PROJETO PROFISSIONAL DO JOVEM NA ÁREA DA BOTÂNICA
}

\author{
Field education and youth professional project in the area of botanics
}

\author{
Rutnéia de Lira Pereira ${ }^{1}$ \\ Maria Jaislanny Lacerda e Medeiros ${ }^{2}$
}

\begin{abstract}
RESUMO: $O$ trabalho consistiu em elaborar um diagnóstico dos estudantes da Licenciatura em Educação do Campo/Ciências da Natureza(LEdoC) e egressos das Escolas Família Agrícola (EFAs) com o Projeto Profissional do Jovem (PPJ) na área da Botânica, além de avaliar os PPJs relacionados à Botânica das EFAs Cocais, Soinho e EFASA. Para tanto, 18 alunos responderam um questionário sobre dados pessoais, escolaridade, moradia, renda, elaboração e execução do PPJ, Botânica e LEdoC. Em relação aos PPJs, foram analisados 28 projetos com temas sobre Botânica, seguindo critérios pré-determinados sobre formatação e estrutura adotados, quanto aplicabilidade e viabilidade. Foram realizadas pesquisas bibliográfica, documental e análise descritiva, com abordagem quali-quantitativa. Verificou-se que os estudantes são, na maioria, jovens, solteiros e filhos de agricultores. Esses discentes mencionaram a dificuldade em continuar o PPJs na comunidade, ressaltando a necessidade de mudanças no formato do projeto. Citaram também, a importância de prosseguir os estudos, principalmente, nos conteúdos relacionados à Botânica, que contribuem para a execução do trabalho, além de sensibilizá-los para a conservação do meio ambiente. Nota-se que a opinião dos estudantes vai ao encontro da Pedagogia da Alternância, utilizadas pelos espaços educativos estudados, os quais aproximam a vida dos estudantes ao trabalho camponês. Dos projetos analisados, foi observada a preferência pelos temas que abordam a produção de hortaliças, milho verde e melancia. Quanto a elaboração dos PPJs, as escolas devem melhorar na contextualização da introdução e da fundamentação teórica, precisam esclarecer melhor a diferença de objetivos e metas, bem como, enfatizar a elaboração da análise comercial, técnica e do estudo financeiro para atingir um planejamento adequado. Ademais, constatou-se que os projetos trazem alternativas que minimizem os impactos ambientais negativos sofridos com atividade agrícola, confirmando a preocupação com a conservação da natureza.
\end{abstract}

Palavras-chave: Escola Família Agrícola. Pedagogia da Alternância. Produção Vegetal.

ABSTRACT: The work consisted of elaborating a diagnosis of the students of the Degree in Rural Education/Natural Sciences (LEdoC) and graduates of the Family Agricultural Schools (EFAs) with the Young Professional Project (PPJ) in the area of Botany, in addition to evaluating the PPJs related to the Botany of Cocais, Soinho and EFASA EFAs. To this end, 18 students answered a questionnaire on personal data, education, housing, income, preparation and execution of PPJ, Botany and LEdoC. Regarding the PPJs, 28 projects with themes on Botany were analyzed, following pre-determined criteria on formatting and structure adopted, as to applicability and feasibility. Bibliographic, documentary and descriptive analyzes were carried out, with a qualitative and quantitative approach. It was found that the students are mostly young, single and children of farmers. These students mentioned the difficulty in continuing the PPJs in the community, emphasizing the need for changes in the project format. They also cited the importance of

\footnotetext{
1 Graduada em Educação do Campo/Ciências da Natureza pela Universidade Federal do Piauí (UFPI). E-mail: ruthneiadl@,hotmail.com

${ }^{2}$ Doutora em Biologia Vegetal pela Universidade Federal de Pernambuco (UFPE). Professora de Biologia do Curso de Licenciatura em Educação do Campo/Ciências da Natureza da Universidade Federal do Piauí (UFPI), Campus Ministro Petrônio Portella (CMPP), em Teresina (PI). E-mail: jaislanny@ufpi.edu.br
} 
continuing their studies, mainly in the contents related to Botany, which contribute to the execution of the work, in addition to raising awareness about the conservation of the environment. It is noted that the students 'opinion is in line with the Pedagogy of Alternation, used by the educational spaces studied, which bring the students' lives closer to peasant work. Among the projects analyzed, preference was given to themes that address the production of vegetables, green corn and watermelon. As for the elaboration of the PPJs, schools must improve the contextualization of the introduction and the theoretical foundation, they need to better clarify the difference in objectives and goals, as well as, emphasize the elaboration of the commercial, technical analysis and financial study to achieve an adequate planning. In addition, it was found that the projects bring alternatives that minimize the negative environmental impacts suffered by agricultural activity, confirming the concern with nature conservation.

Keywords: Agricultural Family School. Pedagogy of Alternation. Vegetable Production.

\section{CONSIDERAÇÕES INICIAIS}

As Escolas Família Agrícola (EFAs) são entidades educativas que promovem o desenvolvimento sustentável do meio rural, mediante a formação dos jovens em um espírito de solidariedade. E, a educação para a cidadania, considerada prioritária por estas instituições educativas, é fator imprescindível para o desenvolvimento sustentável.

A política de formação das EFAs apresenta uma proposta pedagógica em regime de alternância (15 dias no meio escolar e 15 dias na comunidade) voltada para a educação de jovens e adultos, preferencialmente do campo, objetivando a formação humana e profissional, adequada à realidade local, regional e, sobretudo, à cultura camponesa. Nesse sentido, as EFAs buscam soluções viáveis para a problemática do meio rural, integrando o nível médio com o técnicoprofissional, além de usar uma abordagem metodológica do processo de ensino-aprendizagem a partir de experiências do meio rural (SOINHO, 2008).

As EFAs colocam em prática a Pedagogia da Alternância, que se refere a uma forma de organizar o ensino em dois espaços, escola e comunidade, ou seja, o espaço institucional escolar e o espaço ligado à família do aluno (NOSELLA, 2012). A alternância procura conciliar o trabalho da família na propriedade rural com a educação dos filhos, utilizando a interdisciplinaridade, os conhecimentos empíricos e os temas geradores, como formação cidadã e comunitária, meio ambiente e desenvolvimento integral do jovem que vive no campo (GNOATTO et al., 2006). A Pedagogia da Alternância é uma importante alternativa de atendimento à escolarização dos povos que vivem no e do campo (VIZOLLI; AIRES; BARRETO, 2018). Além disso, Hillesheim et al. (2010) ressaltam que os estudantes na escola e junto a família são orientados pelas equipes de monitores, através de instrumentos pedagógicos que integram a participação da família e a convivência com o conhecimento cientifico. 
A partir dessa premissa, as EFAs utilizam alguns instrumentos ou atividades, como o Plano de Estudo, Caderno de Acompanhamento, Caderno da Realidade, Visitas às Famílias, Avaliações e Projeto Profissional do Jovem (PPJ). Dessa forma, os instrumentos pedagógicos da alternância são específicos e de suma importância para colocar em ação o Plano de Formação da escola (SOINHO, 2008).

O PPJ expressa os anseios, as aspirações, a capacidade, as práticas, a teoria e as aptidões de empreendimento do aluno em formação, que visa ser um trabalho prático, aplicável na propriedade ou no mercado de trabalho (SOINHO, 2008). Esse instrumento é o elemento central que deve dar sentido, não somente a formação do jovem, mas a sua vida. Conforme Calvó (2002), esse projeto permite trazer soluções aos seus problemas, e não deve ter o propósito de reproduzir ou copiar ideias, mas concebê-las, criá-las. Dessa forma, o jovem poderá desenvolver suas capacidades, buscar soluções para o seu meio e com seus próprios meios.

Esse projeto é orientado pelo monitor da EFA e busca interagir os saberes e as aprendizagens das diferentes áreas do conhecimento (técnico, social, ambiental, econômica, linguística, histórica, cultural, entre outros), articulando possibilidades de geração de renda para a família, a partir dos estudos e dos diagnósticos de estrutura agrária, administrativa, produtiva, além das necessidades e das potencialidades. A execução do trabalho pode permitir aos alunos egressos a sua permanência no campo.

Os alunos da EFA-Cocais são formados no curso Técnico-Médio em Agropecuária e Agroindústria; na EFA-Soinho em Agropecuária; e na EFA-Santa Ângela (EFASA) em Agropecuária, Agroindústria, Hospedagem (Ênfase em Turismo Rural Ambiental) e em Zootecnia. De tal modo, alguns alunos desenvolvem seus PPJs, com temas da Botânica, principalmente, na área de produção de culturas comerciais e de processamento de alimentos, com ênfase na valorização do meio ambiente e na sustentabilidade.

Segundo Carvalho (2011), a relação do ser humano com as plantas representa uma questão crucial na preservação ambiental, já que, muitas espécies estão desaparecendo, sem que tenham sido estudadas ou conhecido o seu ambiente natural. As plantas e seus derivados estão presentes em vários momentos do nosso dia, desde o despertar até a hora de dormir, entretanto, essa presença nem sempre é notada, o que caracteriza a cegueira botânica (SALATINO; BUCKERIDGE, 2016).

Nesse aspecto, é preciso conhecer e estudar a Botânica de forma mais significativa, com o conhecimento das plantas do seu entorno, pelo entendimento da relação planta-ambiente, além de reconhecer a importância econômica e ecológica dos vegetais. Isso, permitirá que os cidadãos sejam responsáveis pela situação ambiental de forma mais crítica e que possam assumir atitudes mais coerentes com a qualidade de vida que querem ter. 
A necessidade da coexistência sustentável entre o ser humano e o meio ambiente é uma das maiores preocupações contemporâneas. A exploração desmedida dos solos provoca, em muitos locais, a escassez de terras boas para o plantio, inflacionando o preço dos produtos agrícolas e, consequentemente, aumentando a pobreza em determinadas regiões do globo. O desenvolvimento rural sustentável é, atualmente a melhor maneira de usar os recursos naturais de modo que não se esgotem rapidamente (CARVALHO, 2011). E, conforme esse mesmo autor, a sustentabilidade social consiste em um conjunto de práticas que asseguram o desenvolvimento social de maneira concomitante ao crescimento da produção, o que deve ser acompanhado não apenas de números, mas também, de políticas voltadas ao desenvolvimento humano do local, ajudando a diminuir a pobreza rural e as condições sub-humanas de trabalho as quais, infelizmente, muitos trabalhadores estão sujeitos.

Também abordando esse viés de sustentabilidade rural, o Curso de Licenciatura em Educação do Campo/Ciências da Natureza (LEdoC) da Universidade Federal do Piauí (UFPI), que possui a Pedagogia da Alternância (Tempo Universidade e Tempo Comunidade), tem recebido muitos egressos das EFAs, por se assemelhar a proposta de um ensino voltado para o campo.

A Educação do Campo é alicerçada no movimento camponês, na perspectiva da construção de uma educação humana e emancipatória, articulada à vida, ao trabalho, à cultura e aos saberes das práticas sociais dos camponeses. Essa educação promove a formação integral do indivíduo, de forma que valorize o local e as vivências ali desenvolvidas, considerando seus saberes como conhecimento adquirido historicamente. A Educação do Campo não deve se basear em um modelo de ensino pronto para os aprendizes, como se não houvesse uma realidade, história e cultura. Corroborando a questão, Caldart (2003) defende a Educação do Campo, voltada para os povos campesinos, como um ensino que transforme os sujeitos em seu próprio espaço social, passando a compreender esse espaço e sua dinâmica.

A vida no campo, apesar dos impactos do sistema de produção capitalista, não deve ser pensada apenas para obtenção de mão de obra na cidade, mas antes, deve ter uma significativa relação com o próprio trabalho no campo, considerando o contexto campesino e fazendo com que cada aprendiz tenha em mente que pertence a um lugar e que pode transformar o seu meio pela ação, através da consciência de luta pelos seus valores e de que a educação é a porta de entrada para o mundo (SANTOS, 2017).

Os movimentos sociais do campo são de grande relevância na conquista pela terra e, consequentemente, pela educação. Não só há no campo uma dinâmica social ou movimentos sociais, mas também, há um movimento pedagógico. Esse movimento pedagógico surgiu da necessidade de politizar os sujeitos do campo, pois, ao conquistar a terra, é necessário que existam 
escolas para que os campesinos se reconheçam como sujeitos daquela terra e, assim, passem a valorizar a sua cultura (ARROYO, 2004).

Trabalhos desenvolvidos na área de Botânica representam uma alternativa para a melhoria e valorização da vida no campo, podendo integrar a comunidade escolar e a família do aluno. Logo, o desenvolvimento dos projetos elaborados nas EFAs seria imprescindível. Entretanto, alguns egressos das EFAs e estudantes da LEdoC afirmaram que não colocaram seu PPJ em prática, despertando o interesse em conhecer os motivos que os impediram de realizá-los, o que caracterizou o ponto de partida da pesquisa que norteou este estudo. Nesse sentido, acredita-se que este trabalho contribuirá para as discussões sobre a Educação do Campo, a Pedagogia da Alternância, a trajetória dos egressos das EFAs e ingressos na LEdoC e sua formação na área da Botânica, além de propor mudanças no planejamento e execução dos PPJs.

Diante desse cenário, o trabalho consistiu em elaborar um diagnóstico dos estudantes da LEdoC/UFPI, Campus Teresina (PI), egressos de EFAs, com o PPJ na área da Botânica, bem como, avaliar os PPJs relacionados a Botânica das EFAs Cocais, Soinho e EFASA.

\section{MATERIAL E MÉTODOS}

A pesquisa foi UFPI, com alunos do curso de Licenciatura em Educação do Campo/Ciências da Natureza, Campus Ministro Petrônio Portella (CMPP), em Teresina (PI).

O estudo foi executado no período de fevereiro a setembro de 2018. A coleta dos dados ocorreu com estudantes da LEdoC e egressos das EFAs que elaboraram seu PPJ na área de Botânica, totalizando 18 alunos. Para obter o diagnóstico, os participantes responderam um questionário semiestruturado, com perguntas abertas e fechadas sobre dados pessoais, escolaridade, moradia e renda; quanto a elaboração e execução do PPJ; além de questões relacionadas a Botânica e a LEdoC. De acordo com Gil (2008), o questionário é uma técnica de investigação com o objetivo de conhecer opiniões, crenças, sentimentos, interesses, expectativas e situações vivenciadas.

Antes de cada participação, foi explicada a natureza e os objetivos da pesquisa, sendo solicitada a permissão dos partícipes, que estavam cientes de que suas respostas seriam utilizadas para análise da pesquisa. Todos possuíam idade superior a 18 anos e os questionários não foram identificados pelos nomes, garantindo a preservação de suas identidades. Por se tratar de um estudo descritivo, não há riscos legais, físicos, químicos ou biológicos aos participantes.

Em seguida, foram solicitados os PPJs da área de Botânica, para efetuar a análise por meio de critérios estabelecidos previamente, como formatação e estrutura; se as problemáticas estavam de acordo com a temática da EFA; e se houve aplicabilidade e viabilidade do projeto. 
Dentre as várias EFAs, três escolas forneceram seus PPJs na área da Botânica, a EFACocais, situada na localidade Quente, zona rural de São João do Arraial (PI); a EFA-Soinho, localizada na estrada da Cacimba Velha, no Povoado Soinho-zona rural de Teresina (PI); e a Santa Ângela (EFASA), localizada na Rua Candido Pereira da Silva, 271, Bairro Santo Antônio, Pedro II (PI). Foram analisados 28 projetos, sendo 10 da EFA-Cocais, oito da EFA-Soinho e 10 da EFASA.

Para a análise dos dados, foi realizada uma pesquisa bibliográfica e documental. $\mathrm{Na}$ pesquisa bibliográfica é possível conhecer sobre o assunto, procurando referências teóricas publicadas com o objetivo de recolher informações ou conhecimentos prévios sobre o problema; e a pesquisa documental recorre a fontes mais diversificadas e dispersas, sem tratamento analítico (FONSECA, 2002).

Foi utilizada também, uma pesquisa descritiva com abordagem quali-quantitativa. Esse tipo de pesquisa destaca o conhecimento e a interpretação da realidade, por meio da observação, descrição, classificação e interpretação de fenômenos (MALHOTRA, 2019). Na abordagem qualitativa, os fenômenos são melhor entendidos quando o pesquisador vai a campo e busca captar a percepção das pessoas, considerando todos os pontos de vista marcantes para a pesquisa (GODOY, 1995). Dessa maneira, pode-se formular problemas mais precisos ou criar hipóteses que possam ser pesquisadas por estudos posteriores (GIL, 2008). A quantitativa, segundo Fonseca (2002), centra-se na objetividade, considera que a realidade só pode ser compreendida com base na análise de dados brutos, recolhidos com o auxílio de instrumentos padronizados e neutros, a qual recorre à linguagem matemática para descrever as causas de um fenômeno e as relações entre variáveis.

\section{RESULTADOS E DISCUSSÃO}

\subsection{Diagnóstico sobre estudantes da LEdoC e egressos das EFAs}

As Licenciaturas em Educação do Campo (LEdoC) foram planejadas considerando-se as lutas de classe de moradores do campo, colocando-se como parte e ao lado do trabalho desses campesinos, assumindo e defendendo a educação como um direito e um bem público e social. É a partir dessa compreensão sobre a educação, que foram colocadas as perspectivas da formação docente pleiteada pela ação do movimento da Educação do Campo no Brasil.

A necessidade de incorporação de mais tecnologia nos processos produtivos exige trabalhadores mais instruídos, justificando a importância das LEdoC para estudantes do campo. E, nesse sentido, elevar os níveis de instrução dos trabalhadores aumenta simultaneamente os níveis 
de consciência e compreensão das inúmeras contradições sociais que mantêm o sistema capitalista, o que permite um controle cada vez maior dos processos de escolarização (FREITAS, 2011).

Analisando os dados dos participantes da pesquisa, no que se refere a faixa etária, percebese que 55,5\% são jovens entre 18 a 25 anos; 27,5\% possuem de 26 a 32 anos e 17\% apresentam de 33 a 40 anos. Com relação ao sexo, 83,3\% são homens e 16,7\% são mulheres, ou seja, o percentual do sexo feminino é bem mais baixo, o que pode ser explicado, possivelmente, pelo formato de ensino, com aulas práticas de campo que exigem esforço físico.

Em relação ao estado civil, $77,8 \%$ são solteiros e $22,2 \%$ são casados. Os alunos, em sua maioria, estão cursando o primeiro curso superior, representado por $77,8 \%$, enquanto $22,2 \%$ já concluíram outro curso de graduação. No tocante a conclusão do Ensino Médio, 55,6\% concluíram o Ensino Médio na EFASA, 38,9\% na EFA-Soinho e 5,5\% na EFA-Cocais. De acordo com o Projeto Político-Pedagógico (PPP) de uma das escolas estudadas, um dos objetivos da EFA é formar filhos e filhas de agricultores em técnico de nível médio, capacitando-os para prestar assistência técnica aos proprietários rurais (SOINHO, 2008).

No que diz respeito a origem dos alunos, $33,3 \%$ são oriundos de assentamento rurais, $38,9 \%$ de comunidades rurais e apenas $27,8 \%$ da cidade. Portanto, discentes oriundos das comunidades campesinas totalizam $72,2 \%$, ratificando o objetivo de colaborar na construção de um novo homem e uma nova mulher do campo, oferecendo uma educação que seja de qualidade, com ênfase da cultura camponesa e estímulo ao estudo integrado da teoria e prática, valorização do trabalho e da prática social como meios e espaços de aprendizagem, e ponto de partida para o ensino na escola (EFASA, 2018).

Quanto a ocupação, 50\% dos egressos das EFAs estudam e, a outra metade, estuda e trabalha. As EFAs se propõem a diminuir os altos índices de repetência e evasão escolar, além do êxodo rural, buscando conciliar estudo e necessidade de mão de obra familiar no campo. A origem da renda familiar advém de várias fontes, 50\% possui uma única fonte de renda, como trabalho com carteira assinada, trabalho informal, agricultura familiar, aposentadoria ou pensão; 38,9\% possuem duas fontes de renda, trabalho com carteira assinada e complemento com a agricultura familiar, trabalho informal, aposentadoria ou pensão e recebem Bolsa Família; e os outros 11,1\% possuem três fontes de renda, trabalho com carteira assinada, aposentadoria e complementação com a agricultura familiar.

Verifica-se que a agricultara família está presente em todos os grupos. E esse tipo de agricultura está relacionada à legitimação conferida pelo Estado, que criou o Programa Nacional de Fortalecimento da Agricultura Familiar (PRONAF). Esse programa tem a finalidade de prover crédito agrícola e apoio institucional às categorias de pequenos produtores rurais que não tinham 
acesso as políticas públicas e encontravam sérias dificuldades de se manter na atividade (SCHNEIDER, 2003). Para o agricultor participar dessa política pública, é necessário possuir a Declaração de Aptidão ao Pronaf (DAP) e qualquer membro da família que desenvolve atividade agrícola pode adquirir o documento. Pelas respostas dos participantes, 50\% declararam que um membro da família possui, 11,1\% mencionaram que dois membros possuem e 5,5\% citou que três membros possuem, entretanto, $33,4 \%$ falaram que ninguém da família possui a DAP.

Sobre o PPJ, o Trabalho de Conclusão de Curso (TCC) dos alunos da EFAs e que representa uma oportunidade de negócio, uma possibilidade de gerar renda e agregar valor à comunidade (SOINHO, 2008), foi perguntado se houve a sua execução. Foi observado que 22,2\% não desenvolveram, ora por falta de terra e capital próprio, ora por decidirem prestar serviço de assistência técnica. No entanto, $77,8 \%$ dos estudantes revelaram que colocaram seu projeto em prática. Dos que executaram, 44,5\% obtiveram resultados totalmente positivo; 33,3\% parcialmente positivo, mas mencionaram que valeu a pena o desenvolvimento da atividade; e os outros $22,2 \%$ tiveram implicações totalmente negativos, justificaram que foi por razões climáticas e falta de manejo adequado. Qualquer projeto necessita de ajustes ao longo da sua elaboração e execução, principalmente, na parte prática, para minimizar as falhas do plano de trabalho provocadas pela sazonalidade, o que pode maximizar os resultados (DORNELAS, 2011).

Dos que executaram os PPJs, apenas 33,3\% continuam com o projeto até a data da pesquisa, enquanto $66,7 \%$ pararam. Para os estudantes que não continuaram com a produção, foi indagada quais atividades passaram a desenvolver, $12,1 \%$ justificaram pela necessidade de ingressar na LEdoC; $18,5 \%$ pararam por necessidade de trabalhar para sustentar a família; 22,3\% por falta da terra para desenvolver a atividade; $17,3 \%$ por falta de incentivo do governo, pois com resultados diferente dos esperados, as atividades necessitavam de um novo investimento e, sem capital próprio, deveriam adquirir de terceiros, mas o acesso as linhas de crédito tornou-se um impedimento; e os outros 29,8\% não justificaram.

Quando perguntados se fariam alterações em seus projetos, a partir das experiências e conhecimentos atuais, a maioria $(83,3 \%)$ não hesitou e respondeu que "faria alteração para alcançar melhores resultados". A alternativa que mais sobressaiu, 38,9\%, foi planejar e aplicar o projeto, depois avaliava e apresentava os resultados; 33,3\% colocaria o PPJ na matriz curricular do curso como disciplina obrigatória; $11,1 \%$ reformulava o plano e o modelo de apresentação do projeto, dividindo em duas etapas; e 16,7\% não fariam nenhuma mudança, pois os objetivos foram alcançados.

Para haver mudanças no PPP das escolas é necessário um estudo de investigação, principalmente, no que se refere a estrutura física, humana e financeira da instituição. Nesse sentido, $77,8 \%$ dos participantes acreditam que as escolas têm condições de colocar em prática o 
PPJ ainda durante o curso, justificaram que as EFAs contam com uma equipe profissionais qualificadas e disponível, alguns ressaltaram que "o próprio aluno já tem a vivência trazida de casa como ponto positivo para contribuir com a prática" e que "já praticam a atividade agrícola e é responsabilidade do aluno desenvolver o projeto"; enquanto $22,2 \%$ acham que as escolas não têm estrutura, mencionando que "é necessário ser obrigatório na grade curricular", ou que "não é possivel a execução do PPJ pois a escola não dispõem de recursos financeiro suficiente, sendo inviável para os alunos que moram longe manter a produção, elevando ainda mais o custo dos estudos".

No que concerne as perguntas envolvendo a Botânica, os discentes foram inquiridos sobre o tema utilizado nos PPJs, 38,7\% abordaram o cultivo de hortaliças, 33,3\% o cultivo de melancia irrigado, e 5,6\% citaram respectivamente cada experimento seguinte: macaxeira, milho verde, feijão, pimenta malagueta e silagem. Pelas respostas dos alunos, a agricultura familiar possui importância social, econômica, política e cultural para os campesinos, apresentando-se como segmento capaz de responder aos anseios e as necessidades da sociedade brasileira, em termos de abastecimento e justiça social (EFASA, 2018).

No que se refere à contribuição dos conteúdos de Botânica estudados na LEdoC, 83,3\% consideraram benéfico para continuar com o desenvolvimento de seus projetos e 16,7\% não responderam, pois não haviam visto o conteúdo de Biologia Vegetal que é ministrado apenas nos blocos V e VI. Os alunos que consideraram benéfico o ensino de Botânica, elegeram alguns conteúdos abordados como os mais importantes: $37,7 \%$ citaram o estudo da morfologia vegetal; $28,7 \%$ mencionaram o conhecimento e funcionamento das células vegetais; $12,5 \%$ falaram na preservação das plantas no meio ambiente; e 21,1\% apontaram a importância dos processos bioquímicos, as partes vegetativas e reprodutivas das plantas e a fisiologia vegetal. Todos ressaltaram a grande contribuição do conhecimento científico para a cumprimento dos projetos.

Por unanimidade, mesmo os participantes que ainda não cursaram a disciplina, ressaltaram que o conhecimento botânico é de muita relevância para o desenvolvimento, manejo e melhoramento das atividades no campo, sobretudo, porque são alunos da Educação do Campo. O repasse de conhecimento para a comunidade, mudanças de postura quanto a utilização e a conscientização da necessidade de preservação do meio ambiente e todo conhecimento adquirido serão utilizados no dia a dia e no exercício da profissão como educador nas escolas do campo. Dessa forma, o saber cientifico sobre as plantas foi considerado de suma importância para os alunos da LEdoC, confirmado por 100\% dos alunos que já tiveram a disciplina, exemplificado pela menção de um dos alunos: "A Biologia Vegetal pode contribuir com as atividades produtivas junto a família nas comunidades campesinas". 
A opinião dos participantes vai ao encontro da Pedagogia da Alternância utilizadas pelas EFAs e pela LEdoC, que segundo o PPP da EFA-Soinho (2008) é uma pedagogia própria para aliar teoria e prática, sempre partindo de uma realidade concreta, vivenciada pelo jovem e sua família e com instrumentos próprios. Essa pedagogia, que aproxima a vida dos estudantes ao trabalho camponês, é adotada por todas as EFAs do Estado e pelos cursos de LEdoC/UFPI.

Os estudantes citaram os instrumentos mais trabalhados em ambos os espaços educacionais, como o tempo universidade/sessões escolas, tempo comunidade/sessão familiar, visita a comunidade/família, aulas práticas, plano de estudo e místicas, citados por $77,8 \%$; e os outros $22,2 \%$ mencionaram que os serões deveriam ser realizados no espaço universitário.

De acordo com os dados da pesquisa, as EFAs e a LEdoC têm conseguido atingir os interesses dos alunos de forma positiva, atendendo aos filhos e filhas de agricultores. A proposta adotada em regime de alternância contribui efetivamente com o desenvolvimento social e econômico rural, com a valorização da cultura camponesa e combate ao êxito rural. A utilização da metodologia que integra teoria e prática, a contextualização de conteúdos e a interdisciplinaridade, a partir de uso de instrumentos da Pedagogia da Alternância, têm feito a diferença para os alunos relacionados diretamente com o campo. Ademais, o conhecimento cientifico na área da Botânica pode contribuir para o desenvolvimento das práticas produtivas, e o PPJ elaborado nas EFAs pode ser melhor executado com esses conhecimentos, além de ter sido evidenciado a necessidade de mudanças e de organização das etapas do projeto.

\subsection{Avaliação dos PPJs na área de Botânica}

Ao analisar os projetos, foi verificada uma variação quanto ao tipo de produção vegetal nas EFAs (Tabela 1). Na EFA-Soinho, os projetos são dos anos de 2013 (12,5\%), 2015 (75\%) e $2017(12,5 \%)$ e o tema mais abordado foi a produção de hortaliças (25\%). Na EFA-Cocais, os projetos foram realizados em 2012 (10\%), 2015 (70\%) e 2016 (20\%) e o tema mais abordado foi a produção de melancia (40\%); e na EFASA todos os projetos foram do ano de 2016 e o tema mais abordado foi a produção de milho verde (40\%).

Os temas com maior preferência entre as três escolas foram produção de hortaliças, $85 \%$; produção de milho verde, $72,5 \%$, e produção de melancia, $50 \%$ (Tabela 1). Com base nesses dados, ressalta-se que estudantes dessas escolas preferem atividades relacionadas a agricultura familiar.

Tabela 1: Porcentagem de temas da área de Botânica abordados pelos alunos das Escolas Família Agrícola (EFAs)

\begin{tabular}{llll}
\hline Temas & EFA-Cocais & EFA-Soinho & EFASA \\
\hline Produção de melancia & $40 \%$ & - & $10 \%$ \\
Produção de milho verde & $20 \%$ & $12,5 \%$ & $40 \%$ \\
\hline
\end{tabular}




\begin{tabular}{llll}
\hline Produção de feijão verde irrigado & $10 \%$ & - & $10 \%$ \\
Produção de hortaliças & $30 \%$ & $25 \%$ & $30 \%$ \\
Produção de mudas de alfaces & - & $12,5 \%$ & - \\
Produção de quiabo & - & $12,5 \%$ & - \\
Produção de forragem & - & $12,5 \%$ & - \\
Cultivo da mandioca & - & $12,5 \%$ & - \\
Horta econômica & - & - & $10 \%$ \\
Jardinagem & - & $12,5 \%$ & - \\
\hline
\end{tabular}

Quanto ao modelo de projeto, foi investigado se existia um padrão na estrutura e formatação. Observou-se que, na EFA-Cocais, todos os projetos seguem o mesmo modelo, possuem sempre as mesmas etapas, com pequenos ajustes com o passar dos anos, possivelmente para adequação ao tema do projeto e orientação do monitor. Entretanto, mesmo pela similaridade na estruturação, na escrita são bem diferentes e não mantém diálogo com o tempo-escola. Pode-se constatar ainda, que há maior similaridade entre os projetos das EFAs Cocais e Soinho, pois abordam alguns elementos em comum. Mas, apresentam algumas divergências de termos e de contexto, enquanto uma usa estudo econômico e financeiro, a outra usa orçamento. Já na EFASA, o modelo é mais diferenciado, quando comparado as duas outras escolas (Tabela 2).

Tabela 2: Elementos textuais e pós-textuais persentes nos Projetos Profissional do Jovem (PPJs) das Escolas Família

\begin{tabular}{lll}
\hline $\begin{array}{l}\text { EFA-Cocais } \\
\text { (MORAIS, 2015) }\end{array}$ & $\begin{array}{l}\text { EFA-Soińcola (EFAs) analisados } \\
\text { (SCHMIDT, 2015) }\end{array}$ & $\begin{array}{l}\text { EFASA } \\
\text { (SILVA, 2016) }\end{array}$ \\
$\begin{array}{l}\text { Introdução } \\
\text { Realidade Socioeconômico }\end{array}$ & $\begin{array}{l}\text { Introdução } \\
\text { Apresentação }\end{array}$ & $\begin{array}{l}\text { Realidade Socioeconômico } \\
\text { Fundamentação Teórica }\end{array}$ \\
\hline Justificativa & - & Definição (Justificativa) \\
\hline Objetivos, Metas & Justificativa & Objetivos, Metas \\
\hline Análise Comercial & Objetivos, Metas & Análise Comercial \\
\hline Estudo Técnico & Análise Comercial & Estudo Técnico \\
\hline Estudo dos Impactos & Estudo Técnico & - \\
\hline Estudo Econômico e Financeiro & Impactos & Estudo Econômico e Financeiro \\
Conclusão & Considerações Finais & Considerações Finais \\
\hline Referências Bibliográficas & Referências Bibliográficas & Referências Bibliográficas \\
\hline Anexos & - & Apêndice \\
\hline
\end{tabular}

No tocante as regras da Associação Brasileira de Normas Técnicas (ABNT), é perceptível que os trabalhos analisados da EFA-Cocais não seguem as normas, seguindo um padrão de formatação bem distorcido das regras que deveriam sem consideradas. As principais falhas encontradas estão na formatação, descrição das tabelas, além de problemas na lista de referências. 
$\mathrm{Na}$ EFA-Soinho também foi observada falta de formatação e estruturação; foi averiguado ainda, a presença de referências sem citação no texto e a ausência de fontes nas tabelas. Na EFASA, 20\% dos trabalhos analisados estavam de acordo com as normas da ABNT e 80\% apresentavam erros, principalmente na formatação.

Outro ponto investigado foi em relação as normas ortográficas, pode-se observar que existiam alguns erros ao longo dos textos das três EFAs. No que diz respeito ao padrão de orientação aos alunos, observa-se que na EFA-Cocais, não há um padrão, principalmente, no que se refere à formatação, cada orientador segue uma linha de raciocínio diferente. Na EFA-Soinho, também se verifica a falta de padronização, especialmente quando se trata das referências, com presença ou ausência desse elemento pós-textual. Na EFASA, existe uma maior uniformidade, evidenciando que as orientações seguem a mesma lógica, havendo um consenso entre os orientadores.

Passando a analisar se os temas atendem ao objetivo da escola, constatou-se que 100\% dos temas estão de acordo com objetivo das EFAs Cocais e EFASA, respectivamente, "Sensibilizar os profissionais, estudantes, pais, colaboradores, parceiros, prefeituras municipais do território que compreende a EFA Cocais, sobre a necessidade de implementar políticas educacionais e produtivas que favoreçam melhorias na qualidade de vida dos jovens do território” (COCAIS, 2016, p. 16) e "Proporcionar a formação integral, em nível fundamental e médio de crianças e jovens camponeses no sistema da Pedagogia da Alternância em função da promoção do desenvolvimento local sustentável e solidário" (EFASA, 2018, p. 08). Por outro lado, na EFA-Soinho, 87,5\% atendem ao objetivo geral da escola, "Promover e desenvolver o meio rural através da Formação Profissional em Agropecuária de Nível Médio para jovens egressos desse meio, levando em consideração as perspectivas socioeconômicas apresentadas pelas atividades agropecuárias, de transformação e de serviço" (SOINHO, 2008, p. 25); os outros 12,5\% não atendem, por abordar a área de jardinagem voltada para zona urbana, divergindo do objetivo da escola, que é formar técnico que desenvolvam os trabalhos voltados para a comunidade, possibilitando, consequentemente, sua permanência nas comunidades.

Especificamente sobre os elementos textuais, foi examinado se a introdução dos projetos contempla a importância do tema abordado, com a utilização de referências específicas. Para delimitar a investigação foram utilizados parâmetros que deveriam ser abordados para mostrar a importância do trabalho, como origem da espécie, variedade, definição (partes vegetativa e reprodutiva), importância da atividade como fonte nutricional e fonte de renda para produtores, produção (atende as necessidades do mercado, tem produção no mercado atual, quais as técnicas 
de produção ou ainda, a capacidade do mercado consumidor absorve a produção), definição do solo da região, sistema de irrigação, possíveis pragas, prevenção, controle ou combate as pragas.

Com base nos resultados, as três escolas devem melhorar na contextualização da introdução e/ou fundamentação teórica. A pesquisa da literatura é fundamental para o planejamento correto do projeto. O parâmetro "importância da atividade" foi o que mais se destacou, confirmando que os discentes sabem como o projeto pode melhorar a vida da família e da comunidade. As variáveis solo, irrigação, pragas e prevenção precisam ser mais explorados, pois os projetos são de cultivos de espécies vegetais (Figura 1).

Figura 1: Parâmetros adotados para análise da introdução dos projetos das Escolas Família Agrícola (EFAs) Cocais, Soinho e EFASA

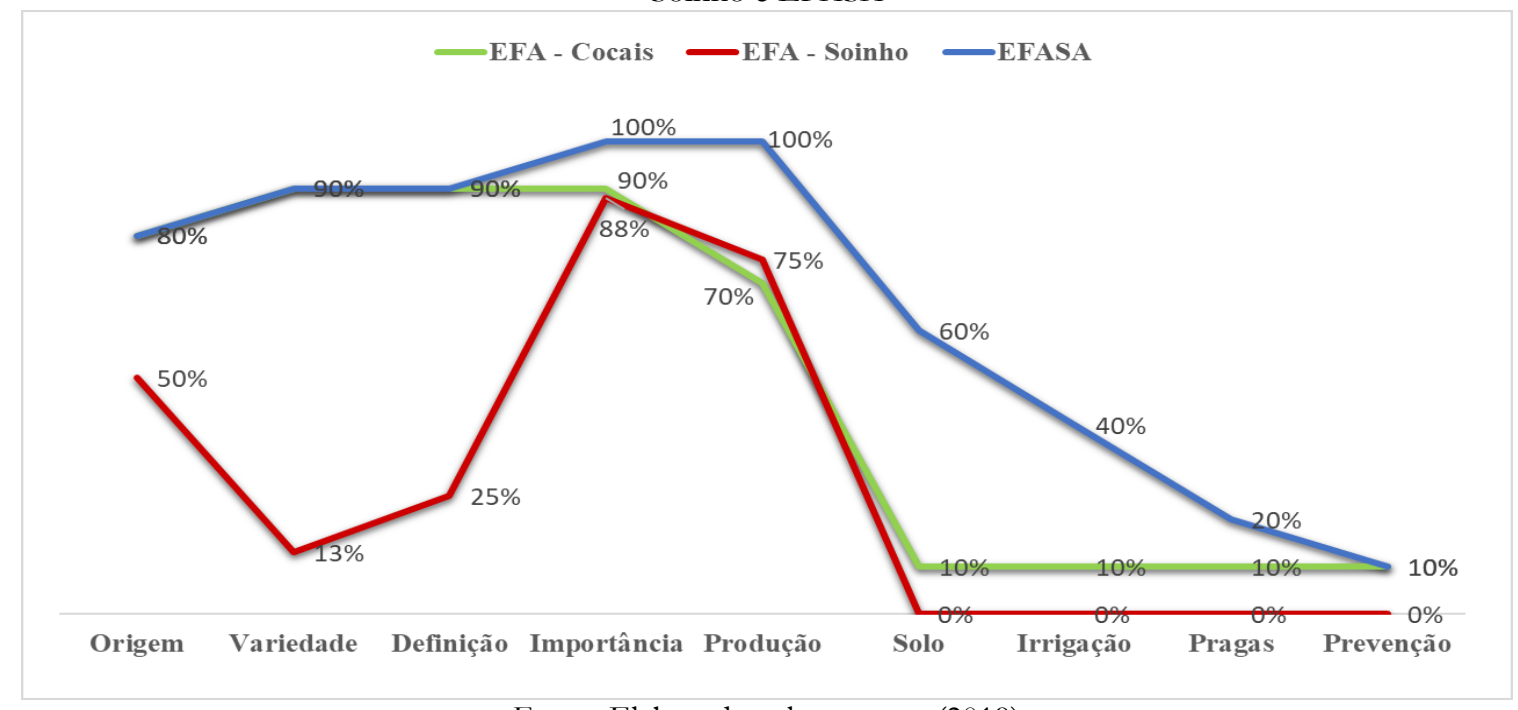

Fonte: Elaborada pelas autoras (2019)

Na EFA-Cocais, 80\% trouxeram uma discussão pertinente para a introdução. Os projetos abordavam principalmente, a origem, a variedade, a definição, a importância e a produção, tendo que melhorar no que refere ao solo, irrigação, pragas e seu combate e controle. Vários projetos abordavam o cultivo irrigado de diferentes espécies vegetais, mas não definiam ou mencionavam sobre a irrigação da cultura escolhida. Na EFA-Soinho, $75 \%$ dos projetos traziam as citações na introdução e $25 \%$ não apresentavam. Os parâmetros mais abordados eram: variedade utilizada, definição da planta, importância da atividade para família, consumidor e mercado, e produção. Mas, percebeu-se a mesma deficiência na EFA-Cocais, em trabalhos com irrigação, esse tema não era abordado, além de não informar sobre o solo, pragas e prevenção. Na EFASA, observou-se uma maior utilização dos parâmetros, chamando atenção também, pelo uso de referencial teórico, o que possibilita um melhor detalhamento e maior abrangência sobre o tema escolhido. Verificou-se que 100\% dos projetos utilizaram citações. A variedade, definição da planta, importância da atividade, produção, solo, irrigação, pragas e sua prevenção estão de acordo com os temas dos projetos 
avaliados. A importância e a produção foram citadas em 100\% dos trabalhos, 90\% descrevem a variedade e definição da planta a ser cultivada, e a origem foi citada em 80\% (Figura 1).

Partindo para a investigação sobre a justificativa, foram definidas algumas perguntas para a avaliação. De acordo com a análise, verificou-se que as justificativas dos trabalhos das escolas EFA-Cocais, EFA-Soinho e EFASA, respectivamente, apresentaram diferentes porcentagens de acordo com as perguntas: Quem se beneficiará com os resultados do seu projeto? (40\%, 25\% e 40\%); O que será realizado no projeto? (50\%, 37,5\% e 90\%); e, Por que escolheu esse tema? (90\%, $87,5 \%$ e $100 \%$ ). Revelando que os alunos definem bem a escolha do tema, mas o que será realizado e quem se beneficiará com os resultados não, pois, na maioria das vezes, são atividades desenvolvidas junto a família.

A próxima análise diz respeito aos objetivos e metas. Para estabelecer objetivos e metas é preciso entender o ambiente externo e interno do negócio, a partir do projeto é possível mostrar se o empreendedor conhece bem seu negócio e o que deve fazer para driblar os fatores externos, sobre os quais deve agir diretamente (DORNELAS, 2011). Diante dessas necessidades, esse mesmo autor ressalta a importância da utilização da análise Swot, que permite traçar um panorama da situação atual e prevista para o negócio. Uma maneira de representar essa análise é pela construção de um retângulo, dividido em quatro partes, em que as forças, as fraquezas, as oportunidades e as ameaças são colocadas separadamente em cada uma. Essa análise permite conhecer o ambiente externo (oportunidade e ameaças) e o ambiente interno (forças e fraquezas). Os objetivos indicam intenções gerais do negócio e o caminho básico para chegar ao destino que se deseja. As metas são ações específicas mensuráveis que constituem os passos para atingir os objetivos (TIFFANY; PETERSON, 1999). Compreende-se que o objetivo geral define o que se pretende com o trabalho de forma ampla e os objetivos específicos apresentam, de forma mais detalhada, as ações que se pretendem alcançar para atingir as metas.

Pelos resultados, foi observado que 100\% dos projetos das três EFAs apresentavam objetivo geral de forma ampla. Na EFA-Cocais, 100\% dos objetivos específicos apresentavam de forma detalhada as ações que se pretendiam alcançar com atividade e 100\% das metas definiam as tarefas específicas e os prazos para aconteceriam. Portanto, a escola define muito bem esses elementos textuais. Na EFA-Soinho, para os objetivos específicos, observou-se que apenas 37,5\% detalhavam as ações, enquanto $62,5 \%$ não tinham esse detalhamento, constatando-se a presença de resultados esperados; quanto as metas, apenas 37,5\% definiam as tarefas especificas e os prazos que aconteceriam. Já na EFASA, 80\% dos objetivos específicos detalhavam as ações e $60 \%$ das metas definiam as tarefas especificas com seus prazos (Figura 2A). 
No comparativo dos resultados, fica evidenciado que o objetivo geral está bem caracterizado nas três escolas, entretanto, existe uma certa confusão entre os objetivos específicos e metas, sobretudo, para os alunos da EFA-Soinho.

Figura 2: Análise dos projetos das Escolas Família Agrícola (EFAs) Cocais, Soinho e EFASA. A - Quanto aos objetivos e metas e B - Sobre a análise comercial

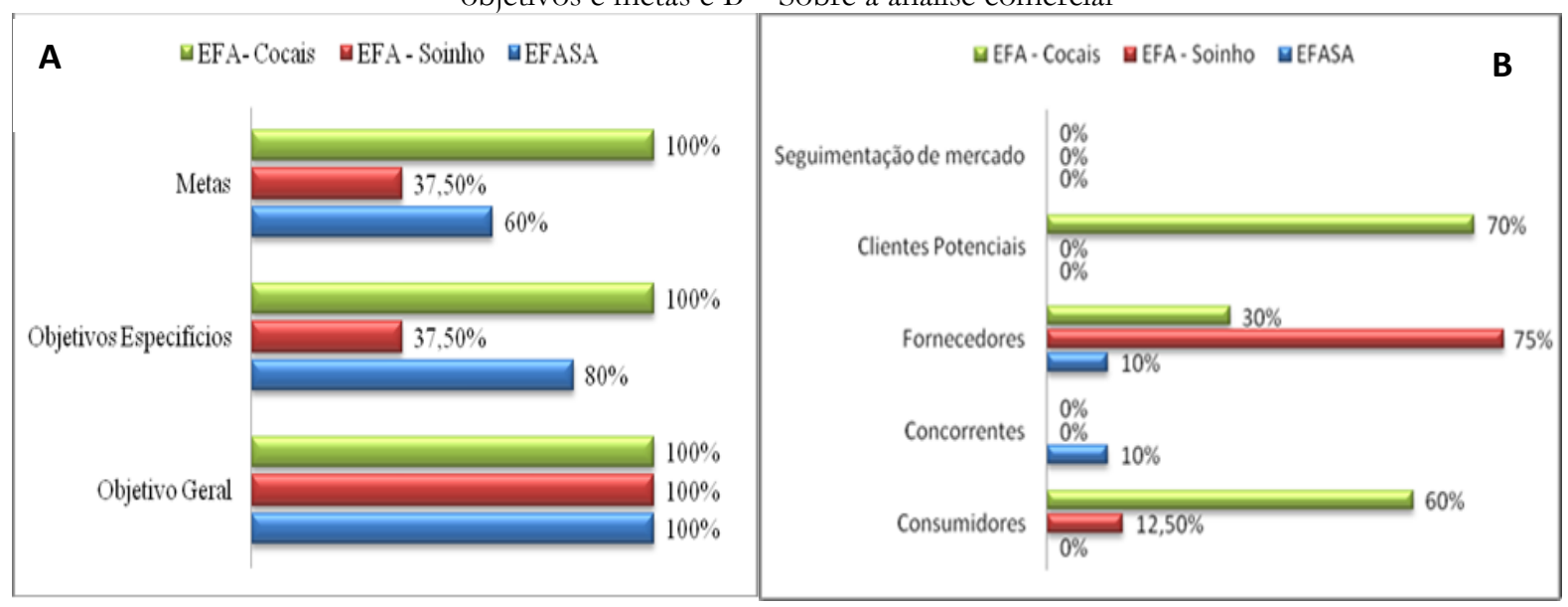

Fonte: Elaborada pelas autoras (2019)

Dando continuidade à investigação, foi observado se a análise comercial descreve o mercado externo onde o projeto irá atuar e se os PPJs abordam essa etapa. A análise de mercado é considerada uma das mais importantes seções de um plano de negócio e deve ser a primeira etapa realizada, todas as outras seções dependem dessa análise. Nessa fase, é conhecido o mercado consumidor do produto ou serviço (através de pesquisas de mercado), como está segmentado, o crescimento desse mercado, as características do consumidor, se há sazonalidade e como agir nesse caso, análise da concorrência, e a sua participação de mercado e a dos principais concorrentes (DORNELAS, 2011).

Pelos dados, verificou-se que a EFA-Cocais abordava as variáveis produto, comercialização, consumo, aceitação, qualidade e exigência, elo da cadeia produção, assistência técnica, mão de obra, mercado fornecedor, mercado consumidor, financiamento do projeto e forma de pagamento do financiamento. De todas as variáveis, somente mercado consumidor e fornecedor contribuem para descrever o mercado externo, as demais se referem a forças, fraquezas e estratégia de marketing. Na EFA-Soinho foram abordados produto, mercado consumidor, mercado fornecedor, plano de vendas, publicidade e sistema de produção. Os projetos dessa escola apresentavam uma análise comercial muito divergente uma da outra. Já na EFASA foram abordadas variáveis como produto, serviços, mercado, sustentabilidade e viabilidade. Todos os projetos foram realizados no mesmo ano, mas com algumas divergências. Entretanto, na maioria, houve a abordagem de forma mais convergente, utilizando as variáveis supracitadas. 
Para quantificar a análise comercial dos projetos, definiram-se as variáveis: consumidores, concorrentes, fornecedores, clientes potenciais e segmentação de mercado. Pelos resultados obtidos, constatou-se que as escolas não descrevem o mercado externo na análise comercial, impossibilitando o conhecimento detalhado do mercado consumidor do seu produto ou serviço (através de pesquisas de mercado), chamando atenção que nenhum dos projetos abordou a segmentação de mercado (Figura 2B). Essa segmentação é importante porque consiste em dividir em estratos - segmentos - de consumidores de um mesmo produto e/ou serviço. Seu objetivo é tornar mais clara e certeira a estratégia de marketing. Essa divisão do mundo dos consumidores segue a lógica de que, por mais que seja um mesmo bem de consumo, as pessoas que compram esses produtos possuem perfis, comportamentos e anseios diferentes, e que tais características norteiam as suas escolhas.

Quanto ao estudo técnico, foi averiguado se esse tópico continha todos os materiais e métodos que seriam necessários para a execução do projeto. Destaca-se que é no estudo técnico do PPJ que se discute o processo produtivo do negócio. O planejamento cuidadoso do plano operacional pode evitar uma série de problemas em relação às instalações da empresa, máquinas e equipamentos, insumos e em relação aos estoques necessários em outros serviços. Embora pareça fácil, é bastante difícil e complexo, exigindo muito planejamento e controle do produtor.

Para proceder a análise foram definidos os critérios: processo produtivo, equipamentos, instalações e insumos. Observou-se diferentes resultados para as três escolas. Na EFA-Cocais, verificou-se os resultados de $80 \%, 100 \%, 80 \%$ e 100\%, respectivamente; pode-se dizer que os alunos sabem bem o que é necessário para implantação do seu projeto. Na EFA-Soinho, foram obtidos respectivamente os resultados $(25 \%, 100 \%, 37,5 \%$ e $62,5 \%)$, entendendo-se que os alunos não conhecem bem o processo produtivo, o que dificulta as instalações e a necessidade de insumos para executar o projeto. Na EFASA, obteve-se respectivamente $(60 \%, 100 \%, 40 \%$ e 100\%), mostrando que os alunos têm mais dificuldades de descrever instalações, pois o projeto é executado na escola, minimizando a busca de informações por essa variável (Figura 3A). 
Figura 3: Análise dos projetos das Escolas Família Agrícola (EFAs) Cocais, Soinho e EFASA. A - Sobre o estudo técnico e B - Quanto ao estudo econômico e financeiro

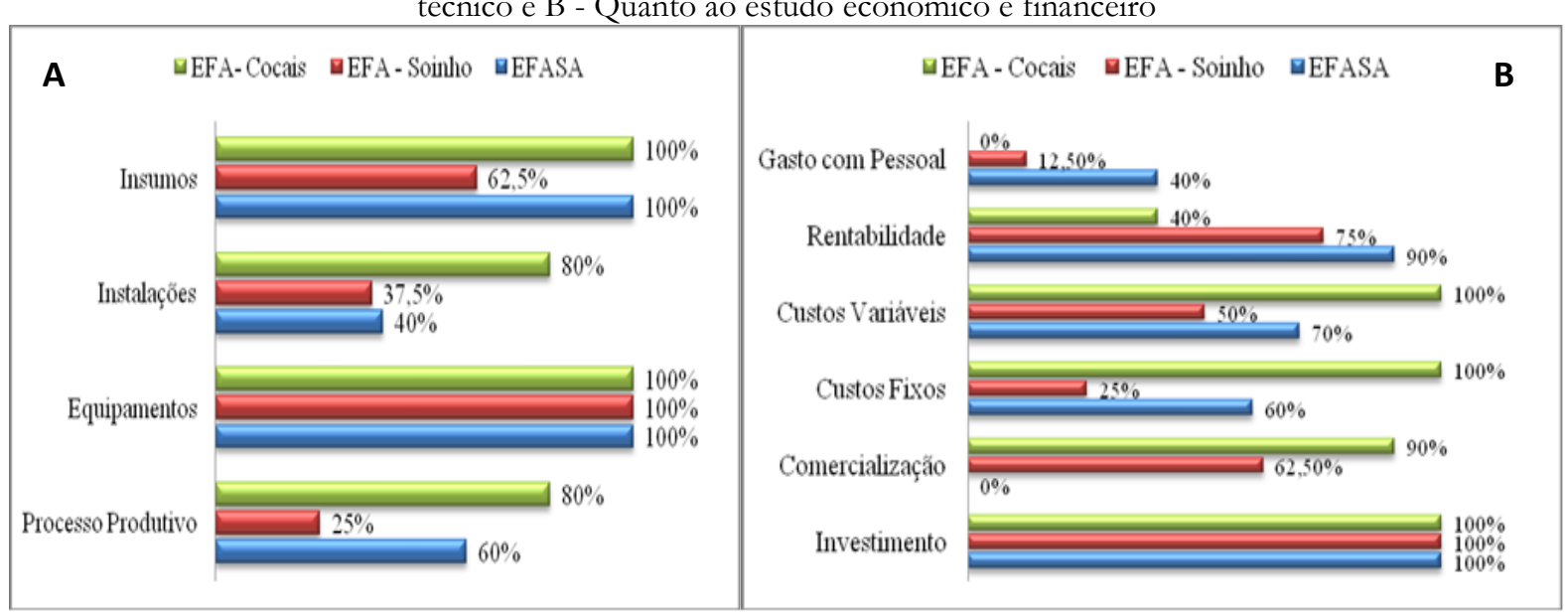

Fonte: Elaborada pelas autoras (2019)

Continuando com a pesquisa, foi investigado o estudo econômico e financeiro, que retrata as condições reais da implantação do projeto. O objetivo básico de um plano financeiro dentro de um projeto é prescrever uma série de projeções financeiras, que acontecerão no negócio ao longo de um tempo, de forma mais realista, para que esse possa transparecer honestidade, credibilidade e racionalidade. Deve refletir em números tudo o que foi escrito nas outras seções do plano, como investimento, gastos com marketing, despesas com vendas, gastos com pessoal, custos fixos e variáveis, projeção de vendas e análise de rentabilidade do projeto (DORNELAS, 2011).

Foi observado que as escolas trazem em seus projetos, o estudo econômico e financeiro ou plano financeiro. Para avaliação, foram definidos os critérios, como investimento, comercialização, custos fixos e variáveis, análise de rentabilidade e gastos com pessoal. O item abordado por 100\% dos projetos nas três escolas foi investimento do negócio. Quanto aos critérios mais ausentes, nos projetos da EFA-Cocais foram gastos com pessoal e rentabilidade, possivelmente, porque as atividades serão desenvolvidas com os membros da família; para a EFASoinho foram gastos com pessoal e custos fixos; e na EFASA foram comercialização, provavelmente, porque os projetos são praticados na escola e a produção é destinada para merenda escolar (Figura 3B). No geral, os dados revelaram que os números utilizados podem comprometer o valor real do investimento.

Para finalizar o estudo, foi pesquisado se os projetos trazem alternativas que minimizem os impactos ambientais negativos sofridos com as atividades desenvolvidas. Na EFA-Cocais foi relatado que há necessidade de minimizar esses impactos negativos ao meio ambiente, como observou-se em um dos projetos: "Será desmatada uma área para instalar o projeto, fazer rotação de cultura, usar defensivos naturais, usar fontes alternativas, como bagana de carnaúba para o controle de plantas daninhas e uso da água com maior controle" (CARVALHO, 2012). 
Alguns alunos da EFA-Soinho demonstraram consciência da necessidade de usar os recursos de forma sustentável, entretanto, outros mencionaram que a execução do projeto não traria mais prejuízos, pois o local já sofreu anteriormente com o desmatamento. Esse pensamento é exemplificado em um PPJ quando o aluno cita "Este projeto tem a vantagem de não provocar nenhum impacto ambiental, pois esta área já vem sendo usada há bastante tempo" (SCHMIDT, 2015). Os discentes da EFASA demonstraram preocupação quanto ao uso de recursos naturais de forma sustentável, além de mostrar uma conscientização no que tange ao reaproveitamento, como observado pela frase retirada de um PPJ dessa escola: "Utilização de insumos antes desperdiçados, aproveitamento da água das chuvas, não uso de agrotóxicos, mínimo de desmatamento, além de reposição de vegetais na área" (PEREIRA, 2016). Logo, foi constatado que as escolas expressam preocupação a respeito dos cuidados com o meio ambiente e a sua conservação.

\section{CONSIDERAÇÕES FINAIS}

Com os resultados obtidos, foi possível identificar que a LEdoC e as EFAs adotam a Pedagogia de Alternância como metodologia para o ensino-aprendizagem de filhos e filhas de agricultores que moram na zona rural. Ainda, alguns instrumentos são adotados no Ensino Superior e Médio, como sessão escolar/tempo universidade, sessão familiar/tempo comunidade, visita a comunidade, aulas práticas, viagens de estudo, serões e místicas. Dessa forma, os instrumentos pedagógicos de alternância demonstram a especificidade desse ensino voltado para os povos campesinos e a sua importância para a formação dos alunos.

Quanto ao diagnóstico dos alunos, metade eram jovens entre 18 e 25 anos, a maior parte eram homens e solteiros, e metade trabalhavam durante a pesquisa. Todos os participantes mencionaram que as atividades relacionadas com a agricultura familiar contribuem com a renda das suas residências. Grande parte dos estudantes eram oriundos das comunidades campesinas. Cerca de $80 \%$ executaram seus PPJs e cerca de $45 \%$ obtiveram resultados totalmente positivos com a prática do projeto. Entretanto, apenas 33\% continuam com a atividade. Além disso, pouco mais de $80 \%$ dos discentes citaram que a partir das informações que possuem atualmente fariam alterações nos seus PPJs, os quais evidenciaram que os conhecimentos adquiridos na área da Botânica, pelos alunos da LEdoC, podem contribuir para o cotidiano da vida no campo e dos sujeitos envolvidos e ainda, otimizar os projetos que estão em execução.

Em relação a avaliação dos PPJs da área da Botânica, ficou claro que as escolas desenvolvem e orientam seus alunos de forma diferenciada e que a falta de alguns parâmetros pode comprometer os resultados. As EFAs precisam esclarecer melhor a diferença de objetivos e metas, 
bem como, enfatizar a importância de uma boa elaboração da análise comercial, técnica e do estudo financeiro para atingir um planejamento adequado para a execução do projeto. A escola que mais se aproximou da proposta ideal de PPJ é a EFASA, pois os professores seguem uma mesma orientação, o que permite maior padronização na elaboração dos projetos, cobram as normas da ABNT, fazem o embasamento por meio do referencial teórico e ainda colocam em prática os projetos na própria escola. Isso possibilita ao aluno a percepção da necessidade de ajustes para alcançar melhores resultados, garantindo sucesso em seu novo empreendimento, o que pode contribuir para a permanência desses sujeitos no campo.

Ademais, como o PPJ é um instrumento de ensino adotado pelas EFAs, embora não tenha caráter obrigatório de execução, é necessário propor modificações para padronizar o modelo do projeto, bem como, para alcançar os resultados esperados daqueles que serão executados, logrando êxito com a sua execução e proporcionando rentabilidade na atividade desenvolvida nas comunidades campesinas dos alunos.

\section{REFERÊNCIAS}

ARROYO, Miguel Gonzalez. A Educação Básica e o movimento social do campo. In: ARROYO, Miguel Gonzalez; CALDART, Roseli Salete; MOLINA, Mônica Castagna (Orgs.) Por uma Educação do Campo. Petrópolis: Vozes, 2004. p. 65-86.

CALDART, Roseli Salete. A escola do campo em movimento. Currículo sem Fronteiras, v.3, n. 1, p. 60-81, jan./jun., 2003.

CALVÓ, Pedro Puig. Formação pessoal e desenvolvimento local. In: Pedagogia da Alternância e Desenvolvimento Sustentável. União Nacional das Escolas Famílias Agrícolas do Brasil, 12 a 14 de novembro de 2002, p. 126-146.

CARVALHO, Edson Ferreira. Meio Ambiente e Direitos Humanos. 2. ed. Curitiba: Juruá Editora, 2011.

CARVAlHO, R. N. A. Projeto de melancia irrigada. 2012. Projeto Profissional do Jovem (PPJ) - Escola Família Agrícola dos Cocais. São João do Arraial, 2012. p. 12.

COCAIS. Escola Família Agrícola. Projeto Político-Pedagógico. São João do Arraial, Piauí: [s.n.], 2016.

DORNELAS, José Carlos Assis. Empreendedorismo: transformando ideias em negócios. Rio de Janeiro: Elsevier, 2011.

EFASA. Escola Família Agrícola Santa Ângela. Projeto Político-Pedagógico. Pedro II, Piauí: [s.n.], 2018.

FONSECA, João José Saraiva. Metodologia da pesquisa científica. Fortaleza: UEC, 2002. 
FREITAS, L. C. Neotecnicismo e formação do educador. In: ALVES, N. (Org.). Formação de professores: pensar e fazer. São Paulo: Cortez, 2011. p. 95-108.

GIL, Antônio Carlos. Métodos e técnicas de pesquisa social. 6. ed. São Paulo: Atlas, 2008.

GNOATTO, Almir Antônio et al. Pedagogia da Alternância: uma proposta de educação e desenvolvimento no campo. In: XLIV Congresso da Sociedade Brasileira de Economia e Sociologia Geral (SOBER): Questões Agrárias, Educação no Campo e Desenvolvimento. Anais... Fortaleza, 23 a 27 de Julho de 2006, p. 01-20. Disponível em: < https://ageconsearch.umn.edu/record/148628/files/941.pdf >. Acesso em: 28 abr. 2020.

GODOY, Arilda Schmidt. Introdução a pesquisa qualitativa e suas possibilidades. Revista de Administração de Empresas, São Paulo, v. 35, n. 6, p. 57-63, 1995.

HILLESHEIM, L. P. et al. Casas familiares rurais: desenvolvimento experiências e práticas de extensão rural através da Pedagogia da Alternância. In: Encontro Nacional de Pesquisa em Educação do Campo III, Anais... 2010, p. 12.

MALHOTRA, Naresh K. Pesquisa de Marketing: uma orientação aplicada. 7. ed. Porto Alegre: Bookman, 2019.

MORAIS, L. V. A. Projeto feijão verde irrigado. 2015. Projeto Profissional do Jovem (PPJ) Escola Família Agrícola dos Cocais. São João do Arraial, 2015. p. 05.

NOSELLA, Paolo. Educação do Campo: origens da Pedagogia da Alternância no Brasil. Vitória: EDUFES, 2012.

PEREIRA, J. P. Produção de Hortaliças (Alface, Cebolinha e Coentro) para a comercialização na comunidade Mãe d'Água. 2016. Projeto Profissional do Jovem (PPJ) Escola Família Agrícola Santa Ângela (EFASA). Pedro II, 2016. p. 14.

SALATINO, Antônio; BUCKERIDGE, Marcos. Mas de que te serve saber botânica? Estudos Avançados, São Paulo, v. 30, n. 87, p. 177-196, 2016.

SANTOS, F. C. Práticas de letramento no campo: a relação da Escola Família Agrícola dos Cocais com uma comunidade rural no Piauí. 2017. 118 f. Dissertação (Mestrado em Letras Estudos da Linguagem) - Centro de Ciências Humanas e Letras. Universidade Federal do Piauí, Teresina, 2017.

SCHMIDT, H. D. Fenação. 2015. Projeto Profissional do Jovem (PPJ) - Escola Família Agrícola do Soinho. Teresina, 2015. p. 14.

SCHNEIDER, Sérgio. Teoria social, agricultura familiar e pluriatividade. Revista Brasileira de Ciências Sociais, São Paulo, v. 18, n. 51, p. 99-122, 2003.

SILVA, W. O. Produção de hortaliças (Alface, Cebolinha e Coentro) no sistema alternativo. 2016. Projeto Profissional do Jovem (PPJ) - Escola Família Agrícola Santa Ângela (EFASA). Pedro II, 2016. p. 07.

SOINHO. Escola Família Agrícola. Projeto Político-Pedagógico. Teresina, Piauí: [s.n.], 2008. 
TIFFANY, Paul; PETERSON, Steven D. Planejamento Estratégico: o melhor roteiro para um planejamento estratégico eficaz. Rio de janeiro: Campus, 1999.

VIZOLLI, Idemar; AIRES, H. Q. Porto; BARRETO, M. Gonçalves. A pedagogia da Alternância presente nos Projetos Político-Pedagógicos das Escolas Famílias Agrícolas do Tocantins.

Educação e Pesquisa, São Paulo, v. 44, p. 01-17, 2018. 